University of Rhode Island

DigitalCommons@URI

Open Access Master's Theses

1992

\title{
Assessment of Maternal Interaction Style as a Precursor to Attachment
}

Maria Schiller

University of Rhode Island

Follow this and additional works at: https://digitalcommons.uri.edu/theses

\section{Recommended Citation}

Schiller, Maria, "Assessment of Maternal Interaction Style as a Precursor to Attachment" (1992). Open Access Master's Theses. Paper 1673.

https://digitalcommons.uri.edu/theses/1673

This Thesis is brought to you for free and open access by DigitalCommons@URI. It has been accepted for inclusion in Open Access Master's Theses by an authorized administrator of DigitalCommons@URI. For more information, please contact digitalcommons-group@uri.edu. 
ASSESSMENT OF MATERNAL INTERACTION STYLE AS A PRECURSOR TO ATTACHMENT

BY

MARIA SCHILLER

A THESIS SUBMITTED IN PARTIAL FULFILLMENT OF THE REQUIREMENTS FOR THE DEGREE OF MASTER OF ARTS

IN

PSYCHOLOGY

UNIVERSITY OF RHODE ISLAND

1992

\#276-141 


\section{Abstract}

Maternal interaction style (often conceived as sensitivity) and security of attachment have long been considered to have an important relationship (Ainsworth et al., 1978; Grossmann et al., 1985; Belsky Rovine, and Taylor,1984; Isabella and Belsky,1991). However, the construct of maternal sensitivity is not consistently defined or measured in the literature. Using videotaped data of 33 mother-infant dyads, we identifed the relevant components of maternal sensitivity as related to attachment outcomes. Data consisted of (1) six weekly naturalistic observations of free-play interaction in the home at 6 month and again at 9 months of age (i.e. 12 assessments for each dyad); (2) face-to-face interactions conducted in the laboratory at 6 and 9 months; (3) Ainsworth Strange Situation at 12 months during a laboratory visit; and (4) a Qsort measure of attachment security. Scoring systems appropriate to each of these assessments were used. Multiple home assessments were used so that a series of observations could be aggregated to form reliable measures of the maternal sensitivity scales.

The effects of age level, setting, and number of observations considered were examined in terms of relation to attachment classification and attachment security measures. Results indicated that (1) aggregation of multiple home observations produces highly reliable and consistent assessment measures (2) laboratory measures are related to home observations (3) neither home nor laboratory observations predict attachment classifications outcomes and (4) home, but not laboratory observations, are related to security of attachment as measured by the Q-sort.

Current findings are discussed in the context of previous attachment research. Methodological as well as theoretical explanations are considered to account for lack of relatedness between maternal sensitivity and attachment outcomes in the current study. 
Acknowledgements

I would like to thank several people who made the completion of this project possible. First, I am particularly grateful to Dr. Ronald Seifer for his continued supervision and assistance. He offered me not only his expertise in statistics, methodology and research design, but also supportive guidance throughout this project. My special thanks to Dr. Larry Grebstein, without whose encouragement and help, this experience, as well as the general demands of graduate work, would be infinitely harder. I would also like to thank Dr. Margaret McGrath and Dr. Charles Collyer for their time, knowledge, and valuable insights during this project.

My thanks also to all my colleagues at The Bradley Family Research Center, who have contributed to this endeavor, directly and indirectly from the beginning. My deepest gratitude goes to the students who helped in the scoring of numerous tapes - Rhonda Boyd, Staci Resnick, and Kate Riordan.

I would also like to add a note of appreciation to the people closest to me: my parents, Mikhael and Sophie Schiller, and my future husband, Gary Belkin, for their unwavering patience, and wisdom. 


\section{Table of Contents}

Abstract ii

Acknowledgement iii

Table of Contents iv

List of Tables vi

Introduction 1

Statement of the Research Problem 1

Research Questions 3

Justification and Significance of the Study 5

Initial Studies of Attachment 5

Replication Studies $\quad 7$

Maternal Attributes \& Attachment 8

Correlates of Insensitivity 9

Correlates of Sensitivity 9

Operationalizing Sensitivity 10

$\begin{array}{ll}\text { Method } & 14\end{array}$

$\begin{array}{ll}\text { Subjects } & 14\end{array}$

Procedures of Infant Temperament Study 15

Procedures and Data Reduction for This Study 19

Results 23

Results of Reliability 23

Home Observations $\quad 24$

Laboratory Observations $\quad 26$

Measures of Attachment 27

Sensitivity and Attachment 28

Discussion 31

Major Questions :- 31

Comparison to Previous Findings 32

Conclusions/Directions for Future Research... 38

$\begin{array}{ll}\text { Tables } & 39\end{array}$

$\begin{array}{ll}\text { Table } 1 & 39\end{array}$

Table $2 \quad 42$

Table $3 \quad 43$

Table $4 \quad 44$ 
Table 5

45

Table 6

46

Table 7

47

Table 8-A

48

Table 8-B

49

Table 9

50

Appendix I

51

Appendix II

52

Bibliography 


\section{List of Tables}

1. Review of Studies: Maternal Sensitivity and Attachment

2. Descriptive Information for Home Observations of Maternal Sensitivity

3. Correlations Between Home Observation Variables of Maternal Sensitivity

4. Average Week-to-Week Correlations of Maternal Sensitivity and Aggregated Correlations over the Six-Week Observation

5. Descriptive Information for Laboratory Observations of Maternal Sensitivity

6. Correlations Between Laboratory Observation Variables of Maternal Sensitivity

7. Correlations Between Laboratory and Home Observation Variables of Maternal Sensitivity

8-A. Mean Ratings on the Laboratory and Home Observation Variables for Each Attachment Group

8-B. Mean Ratings on the Laboratory and Home Observation Variables for Secure and Insecure GroupsMean Ratings on the Laboratory and Home Observation Variables for Each Attachment Group

9. Multiple Regression: Home Observations of Maternal Sensitivity and Q-sort Attachment Security 


\section{Assessment of Maternal Interaction Style as a Precursor to Attachment}

\section{Introduction}

\section{Statement of the problem}

Maternal parenting behavior, characterized as sensitive has been proposed as an important contributor to mother-child attachment. Sensitive parenting has also been associated with beneficial developmental, social and cognitive outcomes for the child, while insensitive parenting has been linked with insecure attachment and less favorable developmental outcomes. Debate continues, however over the proper operationalization of the construct of maternal sensitivity as well as its assessment.

The present study was designed to address some of the methodological issues in assessing the quality of parenting as related to attachment. Most studies to date assess the mother - infant interaction at one or two distinct points during the course of the first year of life, and relate that qualitative measure to the attachment classification at twelve months. It is difficult to establish, on the basis of such investigations, how representative the discrete point of measurement is of the ongoing relationship of the dyad in question. How much does an unusual visit by an experimenter affect the interaction? How peculiar or ordinary was that particular day in the life of the family? More importantly, does the style of interaction evolve or dramatically change over time and if so, how different 
would the findings be if a different age level was chosen for assessment?

Attachment theory presumes accumulated experience on the part of the child (Ainsworth, 1978; Bowlby,1969). When has there been enough accumulation to justify proper assessment? Belsky, Rovine \& Taylor (1984), for example found similar patterns relating maternal style to types of attachment at 6 and 9 months, but only the 9 month results reached significance. Other researchers have found significant relationships with assessments conducted as early as 3 months and 6 months of age (Egeland \& Farber, 1984; Price, 1983 Isabella \& Belsky,1991). Grossmann et al. (1985) suggested that repeated visits to the participants' homes would allow the observers to witness a greater variety of relevant behaviors as well as develop a more accurate perception of usual interactive patterns. There is a lack of clarity, however in terms of the optimal period as well as the number of such assessments that may be necessary to gather a representative sample of interaction style.

The present study directly addressed this methodological issue by conducting a series of home observations around the child's 6th and -9 th month of age. Through these repeated measures three major questions were addressed: (1) Is one time period ( 6 vs. 9 months) relatively more stable or representative in assessing the motherinfant relationship, (2) Is one time period relatively superior in predicting 12 month attachment classification, and (3) Are aggregated measures preferable to single point predictors?

A related methodological issue is that of setting. While some studies compare across observations made in a structured laboratory 
setting with those made in the home, and use one set of observations to predict the other, little is known about the effect of each setting on the measured attachment behavior outcomes. Are laboratory assessments preferable due to increased control over extraneous variables allowed the experimenter? Do such designed and heightened laboratory paradigms bring out the essential qualities of interest? Since attachment classifications are obtained based on a highly structured laboratory procedure, is it more useful to study its precursors with comparable approaches? Are home behaviors better predictors because of the natural setting? As suggested by O'Brien, Johnson and Anderson-Goetz, (1989), this study compared contemporary laboratory face-to-face assessments with extended home observations, to allow for clarification of some of these issues. Using longitudinal, naturalistic observation in conjunction with standardized laboratory assessments the present study addressed the following questions:

\section{Research Questions}

1. Can a reliable measure of maternal parenting style be obtained using repeated observations over time? Aggregated measures for each dyad were evaluated.

2. How are laboratory measures and home observations related? Multiple naturalistic observations in the home were compared with 
one-time evaluations in the laboratory, to evaluate the relationship between the measures.

3. Do either home or laboratory observations have relative superiority in predicting attachment classification? The relative contribution of each assessment method to the subsequent attachment classification at 12 months was considered.

4. Do home or laboratory observations have relative superiority in predicting attachment security according to the Q-sort measure? Both sets of measures were evaluated vis a vis the Q-sort outcome.

5. Does a preferable age level exist in assessing a developing mother-infant relationship in regard to attachment? Six consecutive, weekly observations were made around the 6 and 9 month age level to address this question. 


\section{Justification for and Significance of the Study}

\section{Initial Studies of Attachment}

H A Attachment theory rests on the assumption that maternal sensitivity is one of the primary factors determining a secure mother-infant attachment.) In a classic study, Ainsworth and her colleagues examined the relationship between patterns of maternal sensitivity to infant's cues, over the first year of life, and the quality of attachment observed at 12 months. (Ainsworth, Blehar, Waters, \& Wall, 1978). Sensitive mothers, as defined by Ainsworth and colleagues (Ainsworth, Bell, \& Stayton, 1971; 1974) were able to accurately interpret their babies' cues and respond to them appropriately, promptly and consistently. Ainsworth et al. assert that babies of such mothers, on the basis of accumulated experience, develop the expectation that their needs will be most adequately addressed. Further, they learn that their signals are heard and understood; they develop trust. Secure attachment, then is viewed as an outgrowth, of this basic trust.

\section{Measurement of Attachment}

Ainsworth and her colleagues developed a laboratory procedure designed to classify observed behaviors exhibited by children in response to a series of separations and reunions with his mother in an unfamiliar setting (Ainsworth \& Wittig, 1969). Specified behaviors rated over the course of this Strange Situation procedure generate three general categories:-Secure, AnxiousAvoidant and Anxious-Resistant (Ainsworth, Blehar, Waters, \& Wall, 1978). The two anxious attachment classifications are referred to 
collectively as insecure attachment. These classifications were originally conceptualized by Ainsworth as outcome variables, designed to validate the previously observed patterns of maternal sensitivity in the home.

Since the classifications are based on the child's behaviors and not the mother's, the implicit assumption remains that assessment of the child's behavior in a heightened situation, will reflect and underscore the existing ongoing relationship, as experienced by the dyad. Attribution of a classification, then, does not speak to the components of the relationship or its precursors. The classification of attachment on the basis of the Strange Situation paradigm has become an accepted convention. The construct of attachment along with the operationally defined attachment behaviors as observed in the Strange Situation have been used almost exclusively to index the quality of attachment of a young child to his mother (Pederson et a1.,1989).

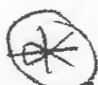

Recently, however, an alternative approach has been suggested and used by some researchers (Waters \& Deane, 1985; Pederson et al., 1989; Vaughn and Waters,1990; Moran et al., in press). The Attachment Behavior Q-sort was introduced by Waters as a way of addressing some of the criticism of the Strange Situation as the sole method of classification of attachment. Lamb et al. (1985), for example, have suggested that too much valuable information collected through observation in the Strange Situation, is ultimately lost by reducing outcomes to a secure/insecure code. Additionally, Waters \& Deane point out that a method of assessment closely related to the child's naturalistic environment is more in keeping 
with Ainsworth's original conceptualization of the attachment system. Not only does naturalistic context provide a more realistic assessment, but Waters \& Deane argue that the attachment system can best be described not by specific behaviors per se, but rather by the adaptability of behavior to a given situation.

The Waters \& Deane Q-sort facilitates this approach. The instrument consists of 90 items. Each item is a description of attachment-relevant behavior derived from theoretical and empirical work on attachment and social cognition. Many items are qualified by specifying a context. These items are printed on cards to be sorted into nine piles according to similarity with the infant's behavior. The completed sort is then compared with the "criterion sort" (a sort of the prototypically secure child, as judged by a series of experts). The resulting correlation is interpreted as a continuous measure of the child's relative security of attachment.

\section{Replication Studies of Maternal Sensitivity and Later Attachment}

Several studies have provided support to the hypothetical association between type of mothering and attachment classification. A close replication of the original Ainsworth study was reported by Grossmann et al. (1985) in a sample of longitudinally followed mother-child dyads in Northern Germany. Using global ratings of sensitivity, developed by Ainsworth et al, the authors found the infants of sensitive mothers more likely to be independently classified as securely attached than infants whose mothers were less sensitive over the course of the first year. 
Concurrent relationship between sensitivity and secure attachment has also been reported (Crockenberg \& McCluskey, 1985; Pederson et al.,1989).

\section{Maternal Attributes and Attachment Classifications}

Some researchers have further explored the relative differences in style and behaviors of mothers of secure vs. anxiousavoidant vs. anxious-anxious-resistant babies. It has been suggested that maternal style of interaction, falling on a continuum according to level of stimulation can serve as a differentiating measure (Belsky, Rovine, \& Taylor, 1984). These authors found mothers of securely attached infants to demonstrate an "intermediate" level of interaction, as compared to the "overstimulation" and "neglect" which characterized the interaction style of mothers of anxious-avoidant and anxious-resistant infants, respectively. Egeland and Farber (1984) describe stable differences among these three sets of mothers in slightly different terms. Caretaking abilities, including general knowledge, timing, and responsivity as well as maternal feelings and attributions about motherhood were considered. As expected, mothers of securely attached babies, were most appropriately responsive, while mothers of anxious-avoidant babies were characterized as "indifferent" and "unavailable". Mothers of anxiousresistant babies suffered more from lack of awareness, than lack of interest, but also failed to provide proper, sensitive care. 


\section{Correlates of Insensitivity}

In examining the extremes of parenting inadequacies, maltreated infants, described as suffering from "caretaking casualty" (Sameroff \& Chandler, 1975), have been found to be more likely than their normative counterparts to demonstrate insecure attachment (Schneider-Rosen, et. al., 1985) and specifically to be classified as anxious-avoidant (Lyons-Ruth et al., 1987). Maltreating mothers were judged as interfering and "covertly hostile" when observed in the home, just prior to the strange situation assessment.

Among the numerous factors studied as predisposing of mothers to a relative quality of parenting have been age, (Ragozin et al. 1982), and depression (Radke-Yarrow et al, 1985; Field,1988; Cohn et al. 1986). Teenage mothers, without proper intervention, have been shown to be at greater risk for displaying insensitive parenting styles leading to increased risk of infant developmental delay. (Field, 1980; Levine, et al., 1983). Maternal depression has been associated with disturbed face-to face interactions as well as insecure infant attachment (Cohn, et al., 1986).

\section{Correlates of Sensitivity}

"Positive" parenting styles have been associated with an array of beneficial outcomes. Cognitive development in both normative and delayed populations has been positively linked with sensitive parenting (Donovan \& Leavitt, 1978; Mahoney, et al., 1985; Bakeman \& Brown, 1980). Beckwith at al. (1976) found maternal sensitivity, in terms of responsiveness and appropriate stimulation, to be related to higher developmental scores for premature infants. Donovan \& 
Leavitt (1978) and Mahoney et al., (1985) and Bornstein and TarnisLeMonda (1988) report similar findings in normative populations. Other beneficial effects of interactive style include social behavior and communication skills in the developing child (Seifer, Clark, and Sameroff,1991) as reflected in more stable, rewarding relationships with mothers (Clarke-Stewart \& Hevey, 1981, Hubbs-Tait, 1987) and peers in later life ( Park \& Waters, 1989; Main, 1983; Patterson, Cohn \& Kao, 1989).

\section{Operationalizing Sensitivity}

In light of this evidence, a closer look at the construct of sensitivity is in order. Noted researchers in the field have emphasized various aspects of the maternal repertoire in their definitions of maternal sensitivity. Accordingly, several terms have been used interchangeably in the literature to refer to the underlying construct of optimal parenting.

As described above, Ainsworth's concept of sensitivity is the appropriate and contingent responsiveness exhibited by the mother to her infant's cues. Ainsworth has relied primarily on naturalistic observations particularly in caretaking situations to arrive at global ratings of relative maternal sensitivity. (Ainsworth \& Bell, 1969). Stern (1974) has focused on the timing and structure of the motherinfant interaction particularly during moments of social play. Attunement is the desired state of mutual responsiveness which is attained by an infant and his mother, provided that the mother is able to perceive the infant's cues and adjust her behaviors to the appropriate level of stimulation. Such interactions, studied in detail 
during face-to-face interactions, are characterized by periods of mutual greeting, engagement and breaks. The sensitivity of the mother in this case would be most closely associated with her ability to tune up or down according to her infant's needs. Insensitive interaction is often characterized by intrusive, or overstimulating behaviors at times when the infant is sending signals for a break, or lack of interesting action when the infant is engaged and clearly available.

Detailed investigation of the face-to-face interaction has been the focus of study of Tronick, Als, \& Brazelton (1980) Cohn, et al. (1986) and Kaye and Fogel (1980). Second-by-second analyses have been used to describe the steps comprising ideal and less ideal mutual involvement of young infants and their mothers in a laboratory setting. Synchrony is the term most often used by these researchers to describe the ideal state where each partner is picking up the cues of the other and interacting accordingly. Imitation of baby's behaviors, appropriate pauses, and mutual gaze are some of the more favorable behaviors observed in synchronous dyads. Fogel and Thelan (1987) point out that the challenge facing the mother lies in the need for continuous adjustment to the growing capabilities of her developing infant. As the infant becomes capable of longer attention span and ongoing stimulation, the mother needs to expand and change her repertoire accordingly at the risk of boring and "tuning out" the infant.

In a similar vein, Belsky (Belsky, Taylor, and Rovine, 1984; Isabella, Belsky \& von Eye, 1989; Isabella \& Belsky, 1991) operationally define sensitivity as Interactional Synchrony, which 
consists of reciprocity of the dyad and the responsivity of the mother. In accordance with attachment theory, Belsky hypothesizes that maternal responsivity to infant's cues lead to a mutually rewarding interaction which in turn leads to the infant's conceptualization of the mother as "available, responsive and trustworthy". According to this model, responsivity and synchrony are the precursors of secure attachment. In fact, maternal responsiveness to infant's cries were the early focus of study in documenting individual differences. Bell and Ainsworth (1972) reported that in their longitudinal sample, infants whose mothers responded to crying quickly and consistently in early infancy, had children who cried less, and used alternative communication more than children of mothers who systematically did not respond in this fashion.

Narrowing the construct even further some researchers have used responsivity alone as an implicit or explicit measure of sensitivity (Crockenberg \& McCluskey, 1985; Lewis \& Feiring (1989). These researchers either distributed self-report questionnaires aimed at assessing responsivity patterns or actually counted frequency of responses on a time sampled basis. In interpreting their results these authors often equate these variables with measures of sensitivity.

By examining recent literature exploring the link between maternal sensitivity and attachment, the variability of conceptualization, as well as design and interpretation of findings becomes evident. Table 1 provides a review of recent and relevant 
studies investigating the relationship between attachment and maternal sensitivity.

Insert Table 1 here

Several points need to be made in evaluating this body of literature as a whole. First, studies vary a great deal in terms of design and assessment methods. Procedures vary from lengthy home observations coupled with informal diary-like recordings, to relatively brief observation periods analyzed through time-sampling methods. In addition, behaviors of interest vary from free-play, feeding, caretaking, or "regular activities" chosen by the mother. Second, the operational definitions of sensitivity range from molecular behavioral counts to global four-point scales. Third, most studies (with two exceptions) are based on relatively small sample sizes. Studies employing large samples (Egeland \& Ferber, 1984; Isabella \& Belsky, 1991) reported an inconsistent pattern of results in terms of types of maternal behavior and observation periods which proved predictive of attachment groups. Finally, there has not been an adequate replication of Ainsworth's original methods in terms of number of repeated, extensive observations, using less subjective measures of sensitivity and a larger sample size.

From this brief review alone, it is apparent that the definition of sensitivity, or its emphasized component not only varies among the studies of attachment, but is also closely associated with the behaviors and methods chosen for investigation. Unfortunately, it is difficult to draw conclusions about the relevance of maternal 
behavior or style, if the conclusions reported in the field are essentially based on a great diversity of constructs as well as settings and methods of measurement.

\section{Method}

\section{Subjects}

Thirty-three mother-child dyads participated in the study. These subjects were participating in a larger study $(\mathrm{N}=50)$ of infant temperament at the Bradley Family Research Center (Seifer, R., Assessing infant temperament using aggregate methods, in progress).

\section{Recruiting:}

Permission was obtained to recruit subjects for the Infant Temperament Project at Women \& Infants Hospital, Providence, RI. A trained research assistant (usually the author) screened the medical records of potential participants to meet the following criteria. All subjects were first born, Caucasian children whose mothers were planning to stay at home at least half time. Families were representative of the working-middle /middle classes. All infants were born without major complications, not requiring time in the intensive care nursery. These characteristics were chosen to ensure a homogeneous sample; infant variables such as race, birthorder and neonatal risk can be seen as confounding factors. Maternal variables including SES, employment status and general stability of the family reflected practical concerns. It was necessary for the 
mother to have adequate motivation and flexibility of schedule to participate in a time-consuming, year-long project.

After initial screening, the research assistant approached mothers individually. The Infant Temperament Study was explained to them in some detail. Those that expressed interest received a one-page description of the study to review with their families. They were also asked to sign a form granting the research staff permission to contact them by phone when the infant was two months old. Every effort was made at the initial recruiting phase, as well as during follow-up phone contact, to include families who were able and willing to participate in weekly home observations and related procedures as part of an extensive longitudinal study. As a final recruiting step, the Principal Investigator, along with a research assistant made an initial home visit to the participating family. Procedures and questionnaires were further explained and informed consent was signed.

\section{Procedures of The Infant Temperament Study:}

The Infant Temperament Study is an extensive, longitudinal project, studying infants during the first year of life. The project involves a variety of procedures and instruments. Only those components which are directly applicable to the proposed study will be discussed in detail. The remaining procedures will be briefly outlined. 
Home visits:

Weekly home visits were made by a female research assistant to the participating families to make three types of naturalistic observations on videotape: (1) child playing alone; (2) child playing with mother and (3) caretaking activities. The same research assistant visited a particular family weekly. She brought with her a small videotape camera, and a standard set of five, age-appropriate toys. Mothers were not specifically instructed about how to play with their infants or whether to use the toys provided. They were informed, however, that a minimum of ten minutes was to be observed for each of the three types of behaviors during the visit. Total length of the home visit was usually between thirty and ninety minutes. Mothers were also asked to complete a series of personality questionnaires at the onset of the study, as well as weekly questionnaires descriptive of the child's behavior. 
Length of Study:

Home visits began when the infant was 3-4 months old and continued until 12-14 months of age.

\section{Laboratory Procedures:}

Mothers made three lab visits with their infants at 6, 9, and 12 months of age. All procedures took place in a standard play room and were videotaped through a window in an adjoining equipment room. The 6-and 9-month procedures were identical and consisted of three parts. First, the Face-to-face procedure (adapted from Tronick et al., 1980) was performed. The procedure consisted of four two-minute episodes. The mother was seated in a chair, 2 feet away from her infant who was placed, facing her, in a car seat ( high-chair is used with larger infants.). The mother was instructed to play with her infant. She was free to interact with the child in any way, including physical touching. However, she was asked not to use toys, and not to take the child out of the seat. The two-minute free-play episode was followed by a still-face episode. The mother was instructed to sit back and remain unresponsive to the infant for the next two minutes. Next was a "reunion", or another free play period followed by a two minute play with "stranger". An unfamiliar adult replaced the mother in her seat and interacted with the infant for the remaining two minutes while the mother observed from the adjoining room. The procedure was abbreviated at any point the child became excessively upset and/or when the mother chose to stop. 
Second, a series of presentations of social and non-social stimuli to the child by an unfamiliar adult. Some examples of these stimuli are talking and cuddling the infant; presenting loud and attractive toys just out of reach and exposing the infant to a tape-recorded cry of another infant. These presentations were made while the child was seated comfortably in the mother's lap.

The final component of the laboratory visit consisted of the three types of behaviors observed weekly in the home, replicated in the laboratory setting. Each type of observation was shortened to 5 minutes so as to keep the length of the lab visit within an hour.

The 12 month laboratory visit, also consisted of three parts. First, the Strange Situation (Ainsworth \& Wittig, 1969) was performed. This is a structured 23-minute paradigm involving a series of separations and reunions of the mother and child, in addition to episodic interactions with an unfamiliar adult, "stranger". Specified behaviors were coded from videotapes to yield a security of attachment classification for each child (Ainsworth, et al., 1978). All scoring for the attachment classification were done by the Principal Investigator of the Infant Temperament Project.

Second, the children were presented with a series of abovedevelopmental-level toys to assess task-orientation.

As in the earlier visits, the final component of the 12-month lab visit consisted of 5 minute segments of each of the behaviors observed in the home. 
The Attachment Q-sort:

Each of the observers who visited the family weekly for the 8 to 10 months of the study, completed the attachment Q-sort following the child's first birthday. As a result of their extensive experience with the child and mother, these observers were quite familiar with the types of behaviors rated by this instrument. Each observer sorted the 90 behavioral statements into nine piles (10 statements each) according to how closely each statement represented the usual behavior of the child. The completed sorts were then compared to the criterion sort of the prototypically secure child to generate a security of attachment rating for each child.

\section{Procedures and Data Reduction for This Study:}

Home Observations:

For each of the 33 participating subjects, 12 video tapes of home observations were reviewed. Six of these were selected around the child's 6 month age level and six additional tapes around the child's 9-month age level. Of these, three tapes chronologically preceded the laboratory visit at each age, and three tapes followed the visits. Six observations were chosen as an appropriate number in terms of the development of a reliable aggregated measure of maternal style.

The goal of the study was to obtain aggregate behavior ratings with acceptable reliability (defined as intraclass $r>.70$ ). This level of reliability can be reached by aggregating six observations, given that the average correlation between pairs of observations is at least $r=$ 
.30. These average correlations were calculated for each of the 3 summary variables at both 6 and 9 month age levels. The actual values ranged from $r=.38$ to $r=.56$. Aggregation of each of these variables over 6 observations yielded intraclass correlations ranging from $\mathrm{r}=.78$ to $\mathrm{r}=.88$, indicating a high level of reliability of the measures.

The Parent / Caregiver Involvement Scale (PCIS), was chosen as the coding system for home behaviors. It was developed by Farran et al., (1986) specifically for periods of interactive play between a mother and her young child (See Appendix I). Other reasons for employing this scale include: reliability and validity information was available and satisfactory; the scale has been used in three previous research projects, including a longitudinal study of young children; ratings were made on a Leikert scale based on specified behaviors observed during the course of the interaction. Such well-defined, yet global ratings (as compared to time-sampled coding of specific behaviors) have been recommended as the superior method for assessing individual differences in patterns of behavior, i.e. maternal sensitivity (Jay \& Farran, 1981; Cairns \& Green, 1979; Waters, 1978).

Scoring of maternal sensitivity was done by viewing the first 10 minutes of the mother and child playing together. The remaining two situations (child playing alone and caretaking) were not scored. because: (1) an initial survey of the data revealed that mothers were often not visible on tape during caretaking and play-alone episodes, and (2), the PCIS is best-suited for scoring interactive play between 
mother and child. This scoring was done by two reliable raters, who remained "blind" to the attachment classifications of the subjects.

Laboratory Observations of Maternal Behavior:

The Face-to Face procedure conducted at the 6 and 9 month laboratory visit was used to compare the interaction style of each mother infant dyad across settings, and situations, The Maternal Sensitivity and Responsivity Scales (Tronick et al., in progress) were adapted, in consultation with the author, for the purposes of this study. These global rating scales were developed specifically for the assessment of maternal response in this structured paradigm. The scale consists of five subscales assessing maternal behavior when the infant's affect is judged as primarily positive or primarily negative. The five subscales are: Control; Intensity; Sensitivity/Elaboration; Dyadic State Regulation; Amount of Joint Activity Each subscale yields a 5-point rating for each episode of interaction viewed. Additionally, global ratings of maternal affect, overall quality of dyadic interaction, and overall pattern of infant affect are made (See Appendix 1I). As in the PCIS, specific behavioral examples are provided to ensure reliable coding. In this study, both episodes of mother-child free-play (total time-4 minutes) were scored. Each tape was scored twice, by two independent raters, who were unaware of the attachment classifications of the subjects. 


\section{Attachment Procedures:}

The Strange Situation conducted at the 12 -month lab visit was scored for security of attachment classification by an independent rater who had no knowledge of the maternal sensitivity scores. Attachment classifications are derived by using detailed behavioral observations, particularly during the reunion episodes between mother and child (Ainsworth, 1978). Children who greet, make positive bids, smiles, or approaches towards their mothers are usually considered securely attached. Children who snub their mothers, by turning away, backing away or ignoring the mother's return generally fall into the avoidant (A) category. Children who express ambivalence by reaching toward mother, but then push away and otherwise resist physical contact, are classified as resistant (C).

Q-sorts of infant attachment were done by independent raters, "blind" to the purposes of this study. Each observer sorted the 90 behavioral statements into nine piles (10 statements each) according to how closely each statement represented the usual behavior of the child. The completed sorts were then compared to the criterion sort of the prototypically secure child to generate a security of attachment rating for each child. 


\section{Results}

Results of Reliability:

Rater reliability was established before final scoring began. Three sets of 10 tapes were reviewed by three raters (the author and two undergraduate psychology students) and acceptable reliabilities on each of the 13 PCIS scales, as well as the total of the 5 impression scores (See Appendix I) was reached. Reliability was calculated using intraclass correlation procedures. Values ranged from $\mathrm{r}=.80$ to $\mathrm{r}=.96$. As this level of reliability is sufficiently high, the home observation tapes were scored by one rater, with any unusual or difficult tapes reviewed by another independent rater, usually the author, for reliability checks.

Similar reliability training procedures as described above were used to establish reliability on the Face-to-Face Scoring procedure (Adapted from Tronick's Maternal Sensitivity Scale). Two raters, (the author and an undergraduate student, unfamiliar with PCIS scoring) scored 3 sets of 10 tapes. Even though raters rarely disagreed by more than 1 point, overall reliability values ranged from $r=.60$ to $r=$ .70. This level of reliability was judged to be inadequate for single scoring, but quite appropriate for double-scoring, allowing for aggregation across the two raters, thus improving reliability to acceptable levels according to the Spearman-Brown correction formulas. All laboratory interactions were scored by the author and one undergraduate student. 


\section{Home Observations:}

Data reduction of the scoring of videotaped free play interaction yielded 3 summary variables for each mother-child dyad. These variables at 6 and 9 months were: Amount of Maternal involvement (AMNT6; AMNT9), Quality of Maternal Involvement (QUAL6; QUAL9) and Appropriateness of Maternal Involvement (APPR6; APPR9). Descriptive information for these variables (means and standard deviations) is provided in Table 2. Correlations among these scales at both 6 and 9 months are presented in Table 3.

\section{Insert Tables 2 and 3 here}

As discussed above, there were 6 observation periods for each dyad around each age level (6 and 9 months). At the 6-month level, average week-to-week intraclass correlations ranged from $r=.41$ to $r=.49$. Six-week aggregation improved reliability to values between $\mathrm{r}=.80$ and $\mathrm{r}=.85$. Similarly, at the 9-month level average week-toweek correlations fell between $\mathrm{r}=.38$ and $\mathrm{r}=.57$. Aggregation across the six-week window provided a highly reliable measure of maternal sensitivity, with values ranging between $r=.79$ and $r=.89$. These correlations are presented in Table 4.

Insert Table4 here 
The dimensions of the scale were found to be highly related. At the 6 months of age, the three measures were highly interrelated; correlations ranged from $\mathrm{r}=.38 ; \mathrm{p}<.02$ to $\mathrm{r}=.96 \mathrm{p}<.00$. Similarly, at the 9 months of age, values ranged from $r=.61 ; p<.00$ to $r=.96 ; \mathrm{p}<.00$. Finally, correlations across ages within each scale were notably high, for amount of involvement: $r=.77 ; \mathrm{p}<.00$; for quality of involvement: $\mathrm{r}=.82 ; \mathrm{p}<.00$ and for appropriateness of involvement: $\mathrm{r}=$ .83; $\mathrm{p}<.00$. Quality and Appropriateness scales, whether within or across age, were al highly correlated. However, the correlations of Quality and Appropriateness with Amount were substantially lower. This pattern of results is to be expected, because "amount" refers to the frequency of maternal response, whereas "appropriateness" and "quality" are both meant to assess the relative sensitivity with which responses are delivered.

Due to high levels of consistency in these measures over time, final summary measures were derived by collapsing across the two ages to give 3 indices of the overall maternal style for each subject (AMNT, APPR, and QUAL).

Laboratory observations:

There were two Face-to-Face laboratory observations for each subject (6 and 9 months). Each session consisted of two 2-minute interactions between infant and mother. These 2 episodes were first scored separately and then collapsed across the two periods to generate the following measures: Sensitivity/Elaboration; Dyadic Regulation and Amount of Joint Activity at 6 and 9 months. In addition to these subscale ratings, global scores of maternal affect and overall quality of interaction were also made at 6 and 9 months. 
Sensitivity summary variables (SENSE6, SENSE9 and SENSE (SENSE6 + SENSE9)) were constructed by summing Sensitivity/Elaboration, Dyadic Regulation, and Amount of Joint Activity at each age level as well as across age levels. Chronbach's alpha indicated adequate consistency among these measures: alpha values were $.95, .92$, and .95 for SENSE6, SENSE9 and SENSE in that order. Descriptive information for all these summary variables is provided in Table 5.

Insert Table 5 here

In final analyses the following variables were used: SENSE6, SENSE9, SENSE, as well as global measures of Maternal Affect and Quality of Dyadic Interaction at 6 and 9 months. Correlations among these variables were calculated and are presented in Table 6. The summary sensitivity ratings as well as the global ratings were highly correlated across the 6 and 9 month assessments, with values ranging from $\mathrm{r}=.31 ; \mathrm{p}<.10$ to $\mathrm{r}=.94 ; \mathrm{p}<.00$.

Insert Table 6 here

Maternal Behavior in Home and Laboratory Settings:

To address the question of how multiple measures of maternal style in the home relate to one-time evaluations in the laboratory, laboratory measures were correlated with the two sets of summary variables from home observations. These analyses allowed for comparison of maternal style in naturalistic vs. structured 
environments and procedures at both age levels. These correlations are presented in Table 7.

\section{Insert Table 7 here}

Generally, all ratings of quality and appropriateness in the home were significantly and positively related to all laboratory ratings of sensitivity. The rating of "amount of involvement" in the home at 9 months was significantly related to concurrent measures of sensitivity as well as concurrent global ratings. It was not significantly related to global ratings in the laboratory at 6 months. The same rating of "amount of involvement" at 6 months was significantly related to laboratory measures of concurrent sensitivity, and global assessments of maternal affect at both ages. These home and laboratory correlations (primarily in the .40 to .50 range) indicated a moderate level of consistency between two sets of sensitivity measures.

\section{Measures of Attachment:}

Three outcome measures of attachment security were used. For the purposes of analysis, the anxious-avoidant and the anxiousresistant groups were combined to yield a two-group classification variable (SECURE). As mentioned earlier, higher incidence of secure classification in middle-class samples, often necessitates this method for approximating equal-n designs (Vaughn and Waters, 1990).

The study was originally designed to include an $\mathrm{N}=30$ (selected from the larger sample $N=49$ ) with 10 subjects representing each of 
the attachment classification groups. However, of the 49 infants classified, 11 or $22 \%$ were "A", 29 or $59 \%$ were "B", and only 8 or $8 \%$ were classified as "C". This distribution is typical for a middle-class, normative sample. To approximate an equal- $n$ design, it was therefore necessary to expand the sample size of this study. Of the 33 participants in this study, 10 were classified as" A"; 15 as "B" and 8 as " $\mathrm{C}$ ". Values on the Q-sort measure of security of attachment ranged from -.68 to .80 with a mean score of $.35(\mathrm{SD}=.29)$.

A continuous variable derived from the Attachment Q-sort (QSEC) provided an independent measure of attachment security. The relation between these two measures of attachment was explored using an ANOVA procedure. Results showed that the insecure and secure groups as distinguished by the Strange Situation classification had significantly different mean scores on the Q-sort measure of security. $F(1,47)=8.04 ; p<.01$. The means for the secure and insecure groups were: $.4507(\mathrm{SD}=.2101)$ and $.2257(\mathrm{SD}=.3435)$ respectively.

\section{Sensitivity and Attachment:}

The primary question in the study was the relative predictive value of the maternal sensitivity measures collected in terms of subsequent attachment classification. To determine the underlying relationship between measures of sensitivity collected at 6 and 9 months in the home and the laboratory, as compared to attachment classification groupings, separate ANOVA's were done. First, the sensitivity measures from the home, from each age level, i.e. Appropriateness, Quality and Amount of involvement were 
compared for the Secure and Insecure groups. No significant differences were found when all three (A, B, and C) groups were considered or when only the binary Secure/Insecure codes were examined. Similarly, when summary variables derived from laboratory assessments were used for the same analyses, again no significant differences among attachment classification groups were found. These findings are presented in Table 8.

Insert Table 8 here

These results indicate that age level variations as well as situational variations in the assessment of maternal style were not useful in predicting attachment classification in the Strange Situation.

A different pattern of results emerged when sensitivity ratings derived from home observations were related to the Q-sort measure of security. Correlations between sensitivity measures and the Qsort measure of security were sufficiently high to warrant further investigation. At 6 months of age the correlations were: $r=.27, r=$. 28, and $r=39$ for Amount, Quality and Appropriateness, respectively. At 9 months of age, the correlations were: $r=.24, r=.26$ and $r=.37$ for the same variables in that order. To determine whether Appropriateness, Quality, and Amount of maternal involvement predicted the security of attachment, as assessed by the Q-sort measure, two multiple regression analyses were done. For the 6 month data, $24 \%$ of the variance in security was explained by the set of predictors. For the 9 -month data $28 \%$ of the variance was explained by the same set of predictors. The predictors were: 
Amount, Quality and Appropriateness of maternal involvement at 6 and 9 months.

Hierarchical multiple regression analyses were also done to determine the relative importance of these variables in predicting attachment security. Appropriateness and Quality variables were added together, since both are qualitative measures of sensitivity. Amount of responsiveness was added separately, as it is a quantitative measure of the frequency of response. At 6 months, Appropriateness and Quality, together explained 24\% of the variance $(p<.01)$. The addition of Amount to the equation, did not result in an increase in R-squared. Similarly, at 9 months Amount and Quality accounted for $28 \%$ of the variance $(\mathrm{p}<.01)$, with the addition of Amount not resulting in significant contribution to the R-squared. However, when Amount was entered first and the set of Appropriateness and Quality was entered second, significant increases in R-squared were obtained. ( $\mathrm{R}$-squared change $=.17$, $\mathrm{p}<.05$ at 6 months; $\mathrm{R}$-squared change $=.23, \mathrm{p}<.01$ at 9 months). These findings are presented in Table 9.

Insert Table 9 here

It is evident from this series of analyses that Appropriateness and Quality, variables assessing relative sensitivity of the maternal response, and not the frequency of responding, as assessed by Amount, contributed the most to predicting Q-sort attachment security. 
Following similar logic, the question of whether laboratory assessments were related to attachment security measured by the Qsort, correlations between laboratory-derived summary measures of sensitivity and the Attachment Q-sort were computed. None of those comparisons proved to be significant or worthy of further investigation.

It should be noted that the results of this study will need to be interpreted cautiously given the small number of subjects currently available. Findings are considered to be exploratory in nature.

\section{Discussion}

This study aimed to address the following major questions: 1. Can a reliable measure of maternal sensitivity be obtained?

The Parental/Caregiver Involvement Scale (PCIS) was used to assess maternal behavior in repeated, weekly free-play observations. Inter-rater reliability of individual sessions was established to anticipated levels. Aggregated measures (over 6 weekly sessions) also proved to be highly reliable, even though week-to-week stability of any two sessions was modest. In addition, analyses of summary variables showed a high level of consistency within all measures, both within and across age level. These findings indicate that aggregation methods are extremely useful in obtaining a methodologically sound measure, which accurately reflects and incorporates the complexities of human behavior over time. 
Laboratory Face-to-Face procedures were scored using a system adapted from Tronick (in progress). Inter-rater reliability was more difficult to establish with this system; two coders were required to obtain acceptable levels of reliability. Several explanations can be considered. First, the Face-to-Face procedure is a highly structured, fairly unnatural situation for both mother and infant. Infants are not normally placed in high-chairs to play, but to eat. Mothers typically engage in play with their infants by holding, cuddling, or moving freely on the floor and using toys for assistance. None of these options are made available to mothers when they engage in the Face-to-Face procedure. Second, this laboratory paradigm allows for only 4 minutes of interaction between mother and infant which is used for scoring. It is quite possible that such a short time interval, in an unfamiliar, unusual setting and structure makes it more difficult to apply the construct of sensitive responsivity to maternal behavior. However, when two raters were aggregated, estimated reliabilities exceeded .80 .

\section{How are laboratory measures and home} observations related?

Results of this study showed that measures collected in the home and in the laboratory were interrelated. Analyses demonstrated a positive relationship for most measures across age levels and across situations. This is an interesting finding given that separate measures were used to assess each situation. In other words, the PCIS, a system specifically designed for periods of longer, free-play interaction was appropriate for tapping maternal style under those circumstances. The Face-to-Face Scoring System was 
designed specifically with the constraints of the situation in mind. Nevertheless, these distinct assessment tools were clearly useful in picking up aspects of the underlying construct of maternal style.

3. Do home or laboratory observations have relative superiority in predicting laboratory attachment classification?

In terms of prediction of attachment classification as judged by the Strange Situation evaluation, both the laboratory measures and the home measures proved to be equally ineffective. Measures of sensitivity, as assessed in the home, were: Quality, Appropriateness and Amount of maternal responsiveness to the child. None of these measures were useful in distinguishing between the Secure, Avoidant, and Resistant groups of children. Similarly, measures such as Amount of Joint Activity, Sensitivity/Elaboration, Dyadic Affect Regulation, as well as global impressions of the quality of interaction and maternal affect in the Face-to-Face procedure were not related to security of attachment.

4. Do home or laboratory observations have relative superiority in predicting attachment security according to the Q-sort measure?

When the Q-sort measure of attachment security was substituted for the Strange situation Classification, as an outcome measure of attachment, a different pattern of findings emerged. Home-based measures of sensitivity were significantly related to the security of attachment, while laboratory measures were not. Interestingly, both the Q-sort and the home-based ratings of sensitivity are measures collected over time, while laboratory 
assessments of attachment in the Strange Situation and of sensitivity in the Face-to-Face paradigm take place during a single observation period. It may be possible that information collected and aggregated over time more closely reflects the complexities of the constructs under consideration, or simply measures the constructs more reliably. One-time observation in unnaturalistic settings may be affected by situational, confounding variables. Goldsmith \& Alansky (1987), for example suggest that the Strange Situation is extremely sensitive to isolated incidents of resistant or avoidant behavior, and that it may not be applicable to children with higher fear/anger thresholds, as the situation would not be sufficiently stressful to trigger the attachment system. These authors conclude that the Strange Situation "may not provide the most sensitive measurement for reflecting prior influences". In a similar vein, Waters \& Deane (1985) advocate Q-sort use for its ability to incorporate the context of behavior into its methodology, as well as minimize observer bias. Generally, Q-sort measures reflect naturalistic behaviors, over time as judged by a knowledgeable observer. This approach parallels our assessment method of maternal sensitivity in the home. Perhaps then, it is not surprising that these measures are more closely related than traditional attachment classification outcomes.

5. Does age level of the child at time of assessment influence the relation of to maternal style and subsequent attachment classification?

According to Attachment theory, it is the accumulated experience over the first year that results in a given attachment classification. It was expected that the 6 and 9 month data would 
explain a comparable portion of the variance in attachment classification, but one would not be more predictive than the other. Results showed that both age levels were equally unrelated to attachment outcomes in the Strange Situation.

However, both the 6 and 9 month data were similarly related to attachment security as evaluated by the Q-sort. More specifically, measures of Quality and Appropriateness of maternal response, at both ages were correlated to attachment security. It appears that judgements made about a child's behavior by an observer, familiar with both the child and mother in naturalistic environment over time, are related to qualitative judgements of maternal behaviors, under similar conditions. In accordance with Attachment theory, one age level was not significantly superior to another in predicting attachment outcomes.

\section{Comparison to Previous Findings:}

Findings in this study were discrepant with some previous work linking maternal sensitivity and attachment classification outcomes. Studies reviewed have reported significant positive relationships between various measures of sensitivity during the course of the first year and attachment classification at twelve months (Ainsworth et al.,1978; Egeland \& Farber, 1984; Belsky, Rovine and Taylor, 1984; Benn, 1985; Grossmann et al., 1985; Crockenberg and McCluskey, 1985; Smith and Pederson, 1988; Pederson et al., 1989; Isabella Belsky and VonEye, 1989; Isabella and Belsky, 1991; Moran et al., in press). A summary review of these studies is presented in Table 1. 
6. Is methodology of this study inadequate in some way as compared to previous work?

In the design of this study careful consideration was given to issues of observer bias, reliability of measures, and assessment procedures. Attachment classifications were done by a trained and reliable, independent rater. Attachment classification distribution for the sample was comparable to previous work with middle class samples, and Ainsworth's original study (Ainsworth, 1978). As described above, measures of maternal style, both in the home and laboratory were carefully selected to reflect the constraints of those situations; they were also found to be highly reliable and consistent over time. All ratings were made by observers unaware of attachment classifications. Q-sort ratings were done by independent observers, unfamiliar with the purposes of this study, based on their almost year-long acquaintance with the child and mother in question. These methodological characteristics, then do not seem to be a probable explanation for our contradictory findings.

One clearly limiting factor of this study, is its sample size. As mentioned above, all findings need to be considered exploratory in nature, until replication with larger samples becomes possible. It should be mentioned, however, that several of the studies reviewed reported comparable sample sizes (Ainsworth, 1978; Benn, 1985; Pederson, 1989; Moran et al., in press).

Some strengths of the current study vis-a-vis previous studies are noteworthy. Of the studies reviewed, few used repeated measures, and none, with the exception of Ainsworth's classic work, 
(Ainsworth, 1978) employed extensive, repeated home visits at various ages. The assessment measures used in this study, were also less subjective than those used by Ainsworth. In her original research, subjective observers, described as "semi-participants" in the lives of the subjects constructed narrative accounts, on which all further rating was based. Although the objectivity of ratings has varied in recent research, the combination of theoretically and methodologically sound assessment measures, with repeated assessments in the home is unique to this study.

Finally, some researchers, (Goldsmith \& Alansky, 1987) have pointed out that the often cited relationship between maternal sensitivity and attachment classification is not as robust as may be expected. Their metanalysis of studies revealed a weak, inconsistent effect for the studies reviewed.

Multiple assessments of attachment security were available for examination in this study. Although the Strange Situation and Q-sort measures were found to be related, (in this study, as well as in previous work [Waters \& Deanne, 1985]) only the Q-sort had significant relationship to the measures of maternal style in this study. These findings are consistent with recent research (Pederson et al., 1989). In addition, the Attachment Q-sort has received attention in recent literature as a more dependable, context-based measure of attachment (Waters and Deanne, 1985; Goldsmith and Alansky, 1987; Smith \& Pederson, 1988). The findings in this study support the notion of the Q-sort as a more sensitive, and methodologically sound measure of infant attachment, at least with regard to its relationship with maternal sensitivity. 
Conclusions/Future Directions in Research:

These findings are by no means conclusive evidence against the link between maternal sensitivity and subsequent attachment security - an underlying assumption, central to current attachment theory. Rather, our findings point to the complexity of the concepts under study. The multi-faceted nature of dyadic interaction as well as individual behavior style, may call for intensive, prolonged observation. It may not be possible to make meaningful statements about these constructs after a single laboratoy-based procedure. As noted above, this study will need to be replicated using larger sample sizes to validate its findings. In addition, many important variables worthy of investigation were not examined in this study. Individual variables pertaining to the mother as well as the child need to be studied. For example, the contribution of the child to the ongoing relationship, i.e. temperamental styles; the contribution of the mother i.e. her emotional and physical health, life stress, attachment history. Finally, family functioning variables, i.e. marital adjustment, sibling systems and overall family environment are undoubtedly important contributors to the developing mother child relationship. The evidence from this study shows that the relationship between maternal style and child-mother attachment is far from linear. Future research will need to focus on teasing apart the other relevant components of this complicated equation. 


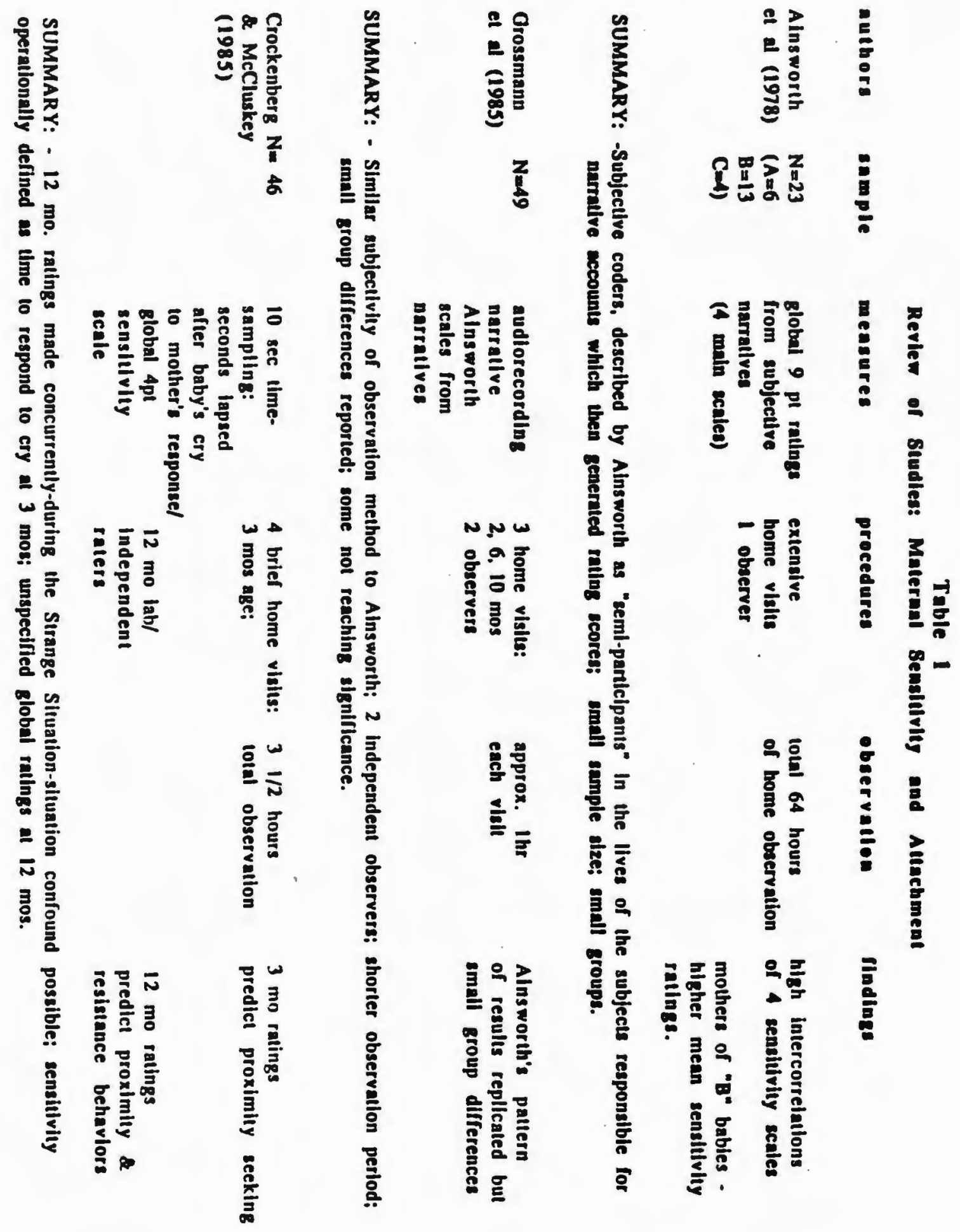




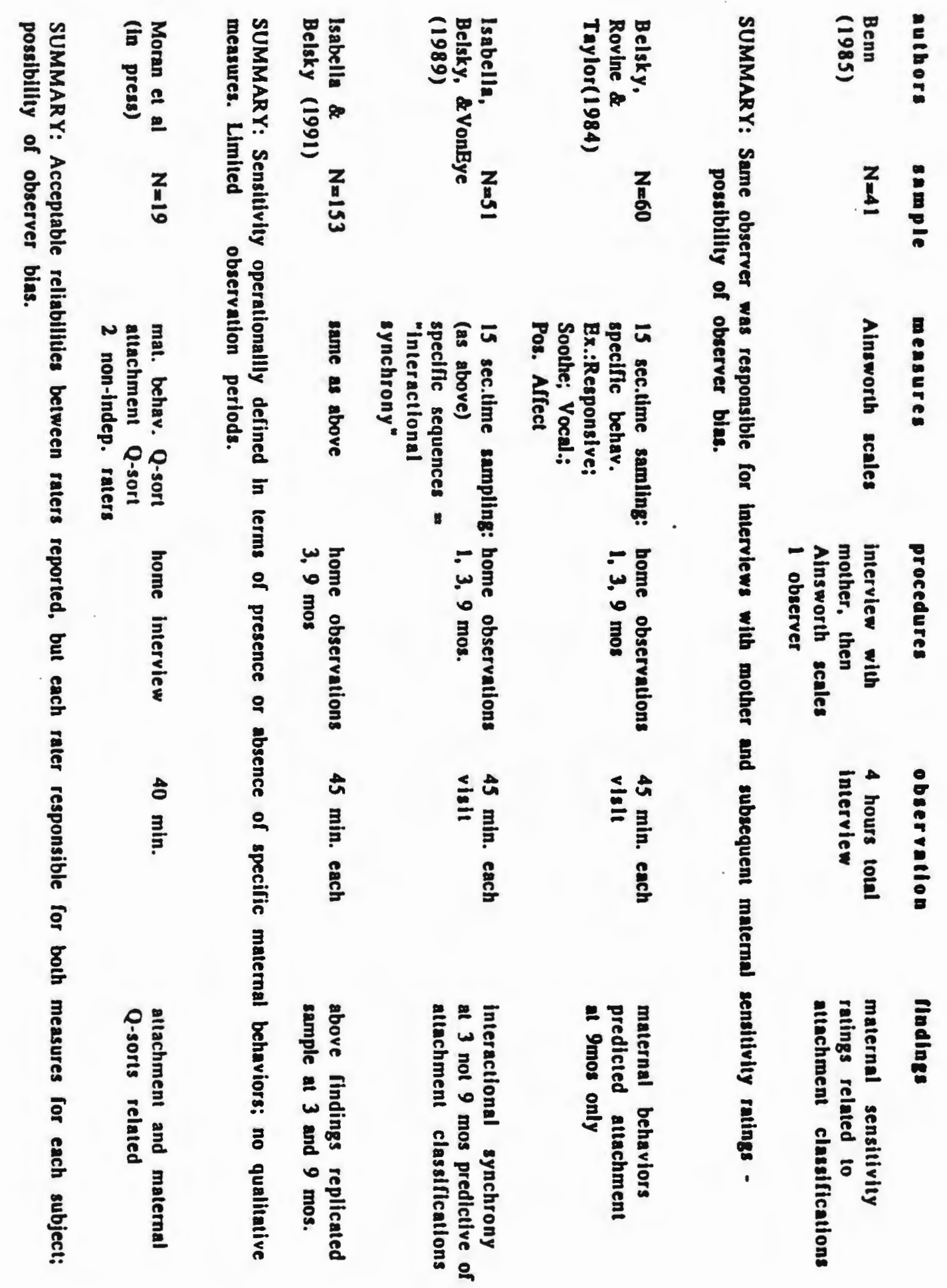




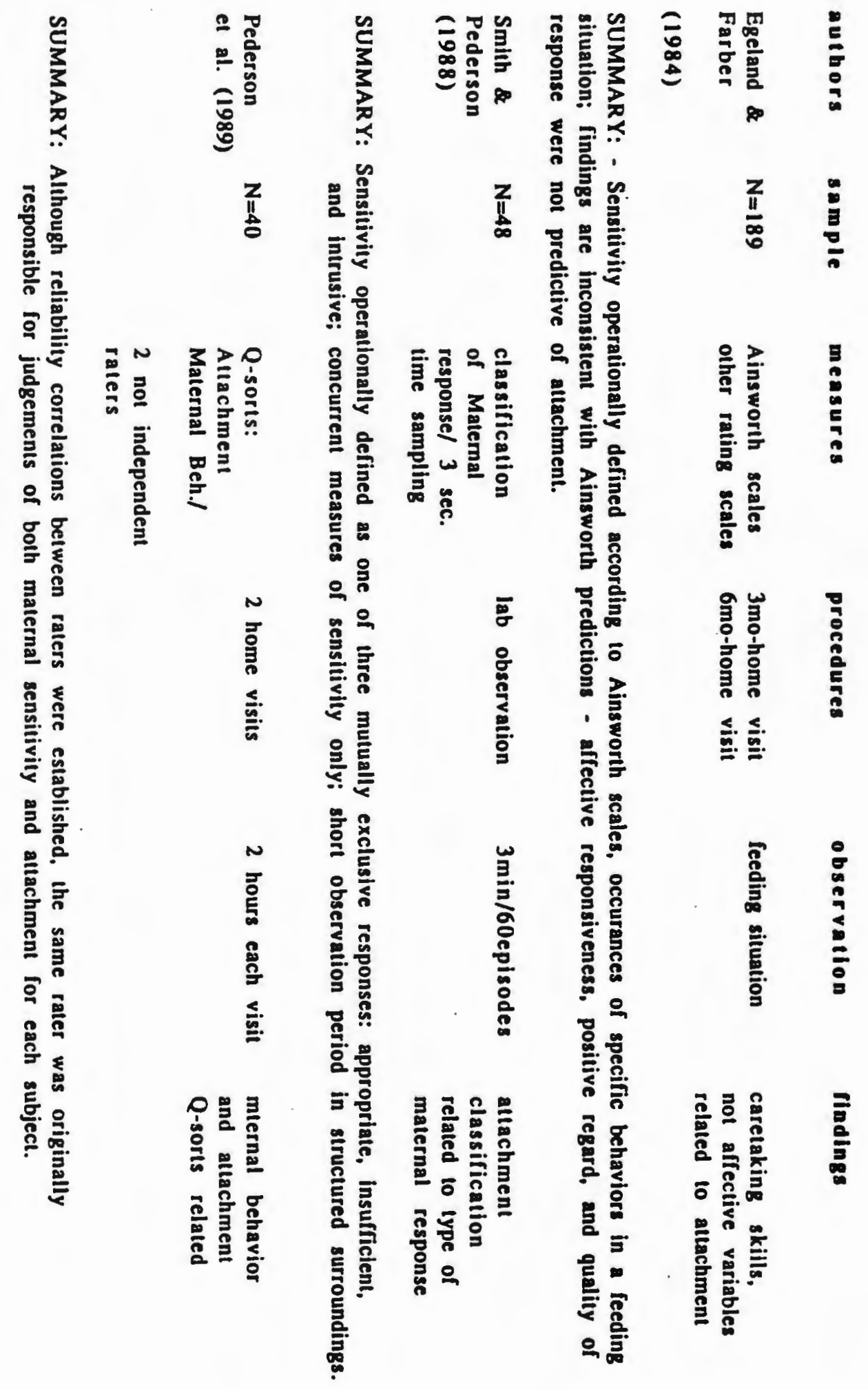


Table 2

Descriptive Information for Home Observations

of Maternal Sensitivity $(n=33)$

\section{AMNT6}

Amount Maternal Involvement:

3.12

0.36

6 mos.

AMNT9

Amount Maternal Involvement:

3.00

0.35

9 mos.

QUAL6

Quality Maternal Involvement:

3.78

0.56

6 mos.

QUAL9

Quality Maternal Involvement:

9 mos.

APPR6

3.73

0.54

Appropriateness Maternal Involvement:

6 mos.

APPR 9

3.75

0.62

Appropriateness Maternal Involvement:

9 mos. 
Table 3

Correlations Between Home Observation Variables

of Maternal Sensitivity

\begin{tabular}{|c|c|c|c|c|c|c|}
\hline & AMNT6 & QUAL6 & APPR6 & AMNT9 & QUAL9 & APPR 9 \\
\hline AMNT6 & 1.00 & & & & & \\
\hline QUAL6 & $.38^{*}$ & 1.00 & & & & \\
\hline APPR6 & $.47^{* *}$ & $.96^{* *}$ & 1.00 & & & \\
\hline AMNT9.78 & & $.55^{* *}$ & $.57^{* *}$ & 1.00 & & \\
\hline QUAL9 & $.36^{\star}$ & $.82 * *$ & $.84^{* *}$ & $.61^{* *}$ & 1.00 & \\
\hline APPR 9 & $.36^{*}$ & $.78^{* *}$ & $.83^{* *}$ & $.61 *$ & $.96^{* *}$ & 1.00 \\
\hline
\end{tabular}

Note: Significance tests are two-tailed.

$p<.05$
$* p<.001$ 
Table 4

Average Week-to-Week Correlations of Maternal Sensivity

and

Aggregated Correlations Over the Six-Week Observation

Variable

Week-to-Week

6-Week Aggregate

AMNT6

.41

.80

QUAL6

.49

.85

APPR6

.44

.82

AMNT9

.38

.79

QUAL9

.56

.88

APPR9

.57

.89 
Table 5

Descriptive Information for Summary Variables

for

Laboratory Observations of Maternal Sensitivity ( $\mathbf{n}=33$ )

Variables

SENSE6

Sensitivity + Dyadic Regulation +

Joint Activity: 6 mos.

SENSE9

Sensitivity + Dyadic Regulation + Joint Activity: 9 mos.

SENSE

Sensitivity + Dyadic Regulation +

Joint Activity: $6+9$ mos.

RATING64

Global Rating: Maternal Affect

6 mos.

RATING65

Global Rating: Dyadic Interaction 6 mos.

RATING94

Global Rating: Maternal Affect

9 mos.

RATING95

Global Rating: Dyadic Interaction 9 mos.
Mean Standard Deviation

20.18

5.10

19.70

4.15

39.94

7.71

3.45

0.47

3.26

0.88

3.55

0.46

3.07

0.71 


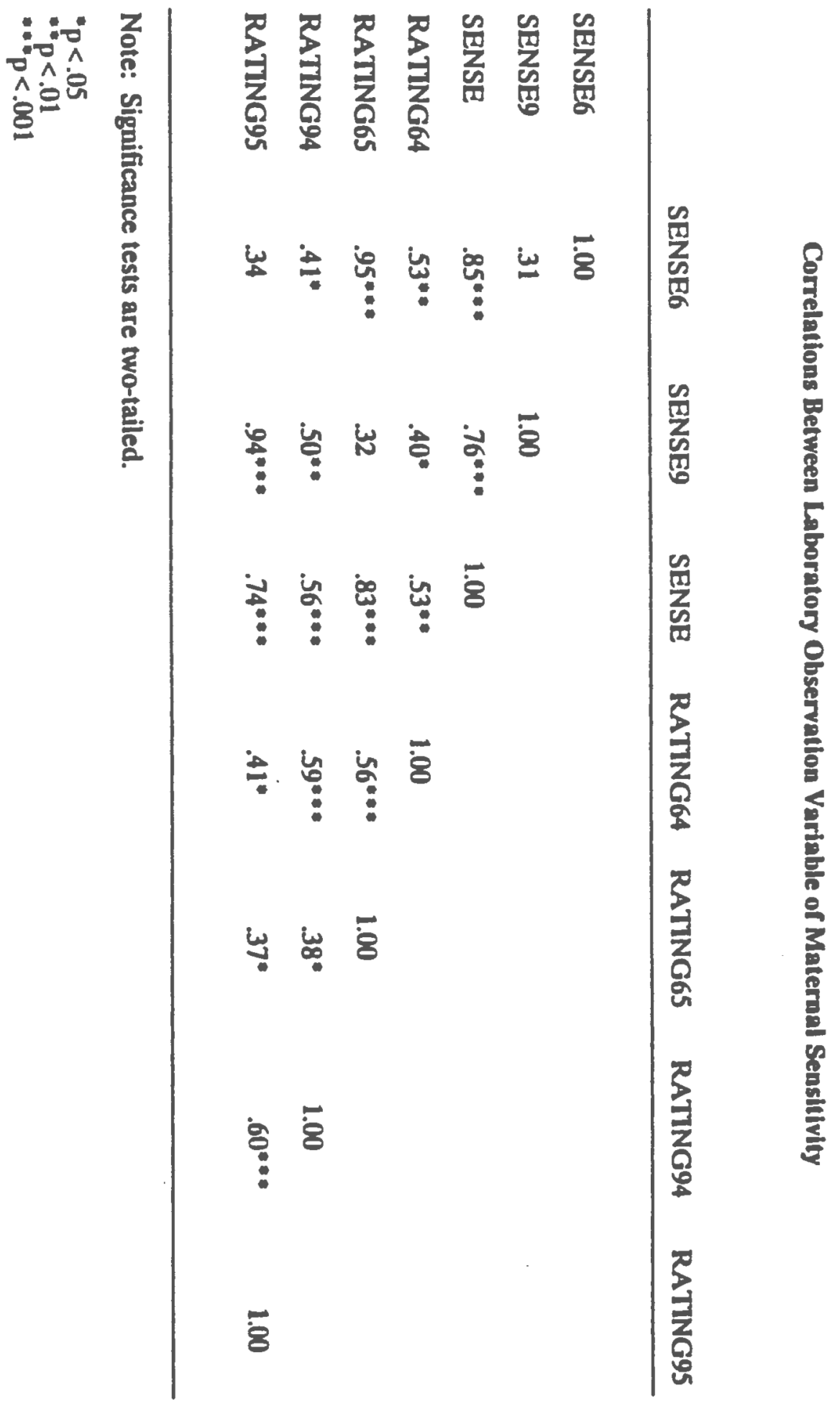




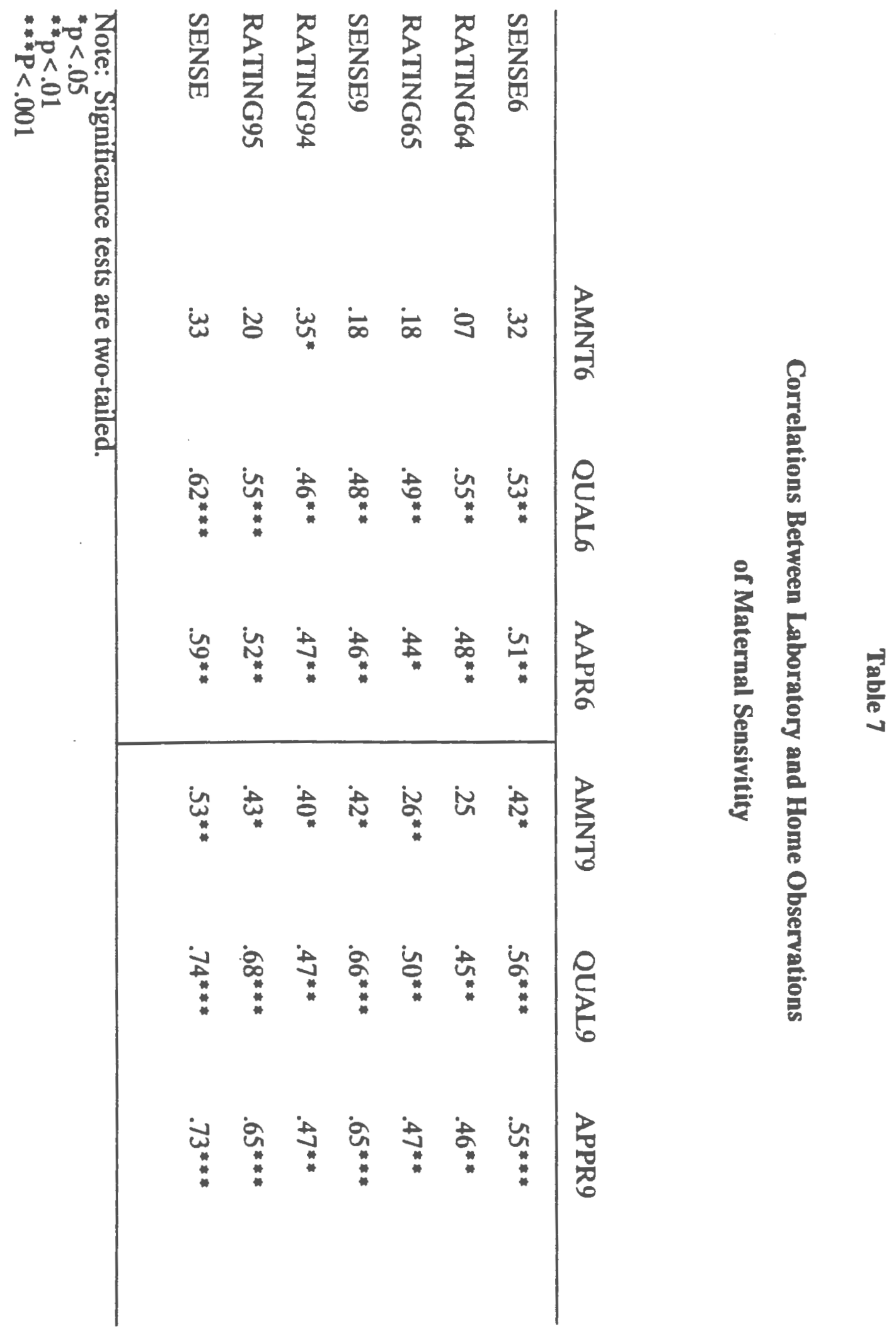


Table 8 - A

Mean Ratings on the Laboratory and Home Observation Variables for Each Attachment Group at 12 Months

Variables

A

B

C

F-Ratio

$\mathbf{P}$

Home:

$\begin{array}{llllll}\text { AMNT6 } & 3.19 & 3.08 & 3.09 & .32 & .73 \\ \text { QUAL6 } & 3.78 & 3.69 & 3.92 & .45 & .64 \\ \text { APPR6 } & 3.73 & 3.67 & 3.85 & .29 & .75 \\ \text { AMNT9 } & 3.10 & 2.96 & 2.96 & .62 & .54 \\ \text { QUAL9 } & 3.70 & 3.77 & 3.84 & .11 & .89 \\ \text { APPR9 } & 3.64 & 3.77 & 3.83 & .21 & .80\end{array}$

Lab:

$\begin{array}{lrrrrr}\text { SENSE6 } & 18.72 & 20.43 & 21.37 & .58 & .56 \\ \text { RATING64 } & 3.40 & 3.43 & 3.56 & .27 & .76 \\ \text { RATING65 } & 2.90 & 3.40 & 3.43 & 1.21 & .31 \\ \text { SENSE9 } & 19.20 & 20.30 & 19.56 & .27 & .77 \\ \text { RATING94 } & 3.50 & 3.40 & 3.87 & 3.31 & .06 \\ \text { RATING95 } & .3 .08 & 3.07 & 3.06 & .00 & .99 \\ \text { SENSE } & 37.30 & 41.25 & 40.94 & .75 & .47 \\ & & & & & \end{array}$


Table $8 \cdot$ B

Mean Ratings on the Laboratory and Home Observation Variables for Secure and Insecure Groups at 12 Months

Variables

Secure

Insecure

F-Ratio

$\mathbf{P}$

Home:

AMNT6

3.08

3.14

.17

.68

QUAL6

3.67

3.84

.70

.41

APPR6

3.67

3.76

.22

.64

AMNT9

3.03

2.96

.39

.54

QUAL9

3.77

3.77

.00

.98

APPR9

3.77

3.73

.02

.88

Lab:

SENSE6

20.54

19.92

.11

.74

RATING64

3.43

3.47

.07

.79

RATING65

3.43

3.13

.92

.34

SENSE9

20.31

19.26

.47

.49

RATING94

3.43

3.63

1.62

.21

RATING95

3.11

3.04

.06

.80

SENSE

41.25

39.01

.58

.45 
Table 9

Multiple Regression: Home Observations of Maternal Sensitivity and Q-Sort Attachment Security

\begin{tabular}{lccc}
\hline \hline 6 MONTHS & & \\
STEP & $\begin{array}{c}\text { VARIABLES } \\
\text { ENTERED }\end{array}$ & $\begin{array}{c}\text { TOTAL } \\
\text { R-SQUARED }\end{array}$ & $\begin{array}{c}\text { CHANGED } \\
\text { IN R-SQUARED }\end{array}$ \\
1. & APPR6 & $.24^{*}$ & \\
2. & QUAL6 & $.24^{*}$ & .00 \\
\hline 1. & AMNT6 & .07 & \\
2. & AMNT6 & & $.17^{*}$ \\
\hline \hline
\end{tabular}

9 MONTHS

$\begin{array}{cccc}\text { STEP } & \text { VARIABLES } & \text { TOTAL R- } & \text { CHANGED IN } \\ & \text { ENTERED } & \text { R-SQUARED } & \text { R-SQUARED }\end{array}$

1.

APPR9

QUAL9

$.28 * *$

2.

AMNT9

$.29^{*}$

.01

1.

AMNT9

.06

2.

APPR9

QUAL9

$.29 *$

$.23 * *$

$* \mathrm{p}<.05$
$* \mathrm{p}<.01$ 


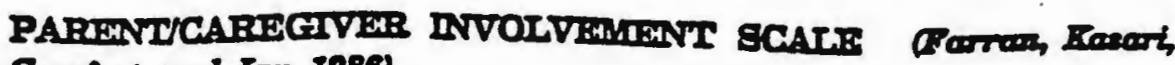 \\ - Comfors and Jay, 1988)
}

Name/10

Todoste Date $\frac{1}{10}$

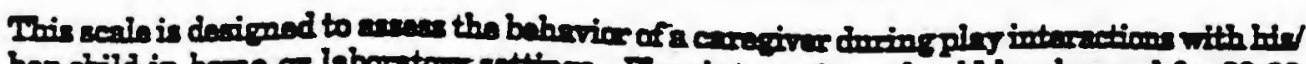

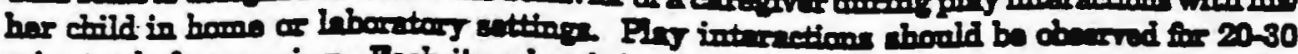

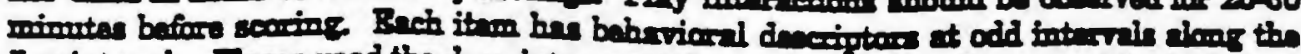

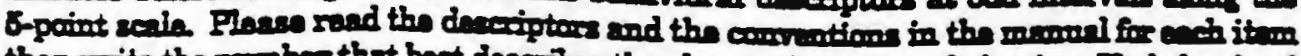

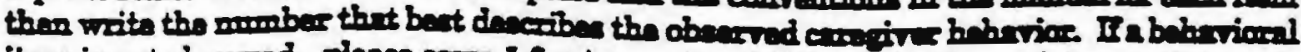

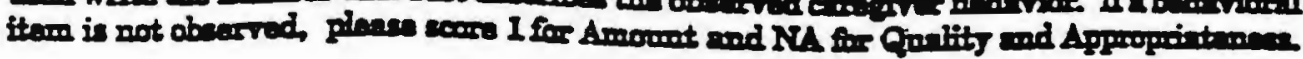

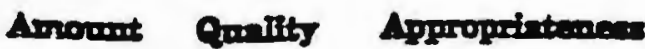

Phycical Irvolvanemt

Veabal Irvatrumant

Bapensivenes of Cerrepiver to Child

ENg intaration

\author{
Control of Activitie \\ Diroctive Deromis \\ Rintionsing mone Activitio \\ Paritive Btatmonate, Bopard \\ Nopativ Btatemontan, Bepred \\ cal settons
}

$\triangle Q A$ Sobenio Tutis AQA MEANB

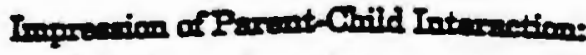

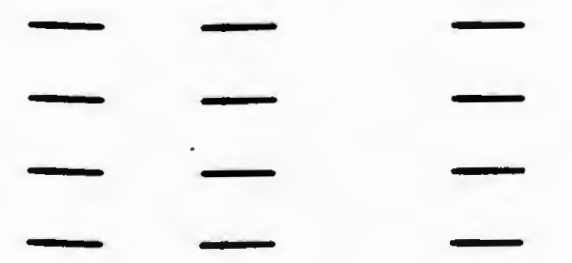

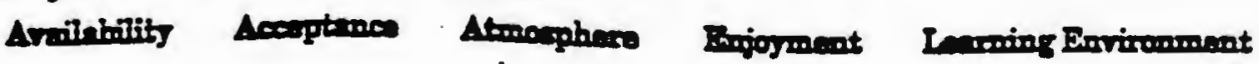

Inpreasion Total

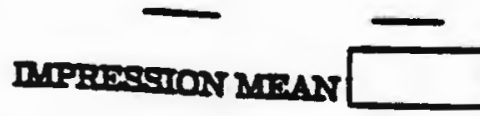


APPENDIX II

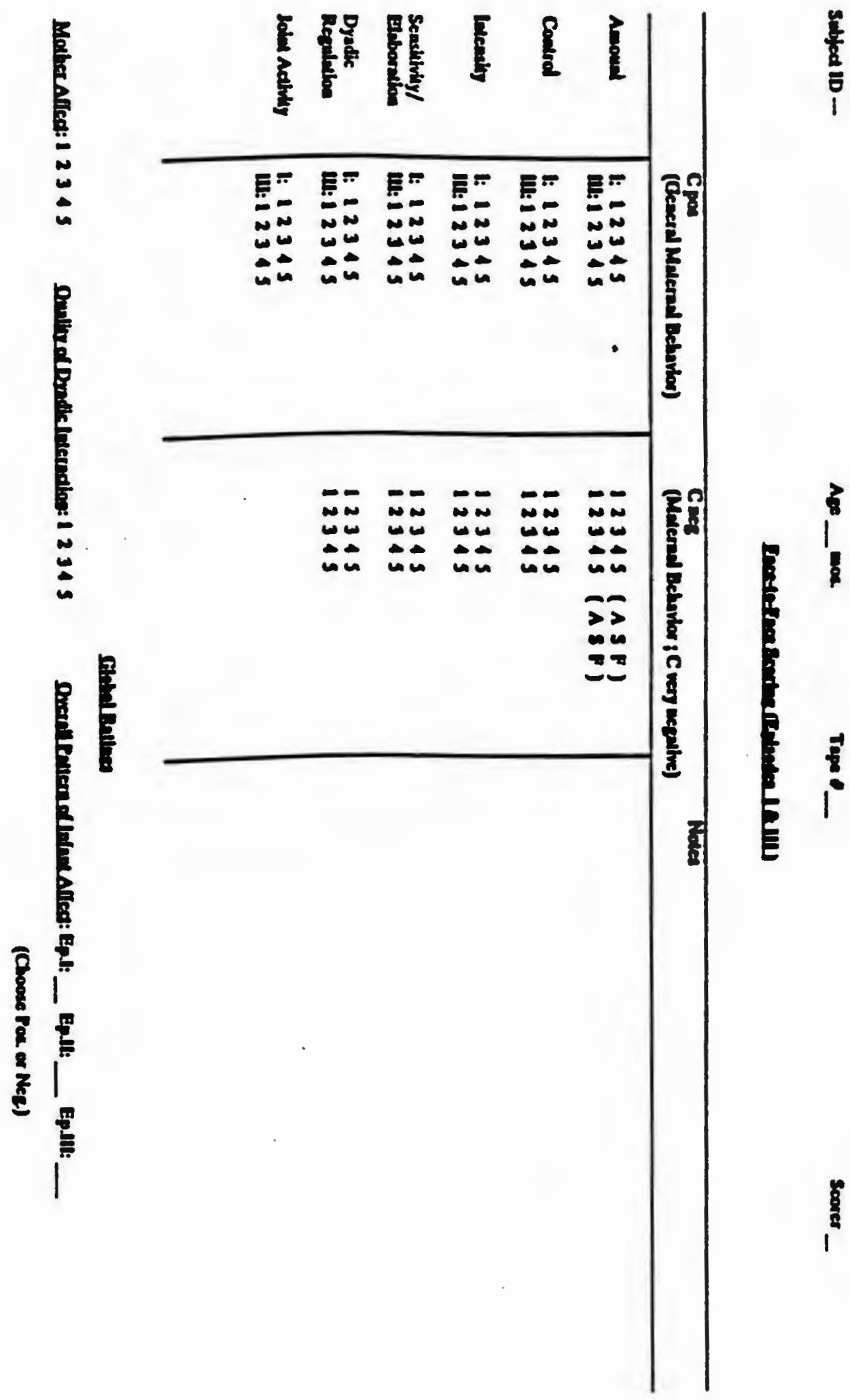




\section{BIBLIOGRAPHY}

Ainsworth, M. D. S., \& Bell, S. M. (1969). Some contemporary patterns of mother-infant interaction in the feeding situation. In A. Ambrose (Ed.), Stimulation in early infancy. New York: Academic Press.

Ainsworth, M. D. S., Bell, S.M., \& Stayton, D. J. (1972). Individual differences in the development of some attachment behaviors. Merrill - Palmer Quarterly, 18 (2), 123-143.

Ainsworth, M. D. S., Bell, S.M., \& Stayton, D. J. (1974). Infant-mother attachment and social development: "socialization" as a product of reciprocal responsiveness to signals. In M. Richards (Ed.), The integration of the child into a social world. New York : Cambridge University Press.

Ainsworth, M. D. S., Blehar, M. C., Waters, E., \& Wall, S. (1978). Pattems of attachment: A psychological study of the strange situation. New Jersey: Hilsdale.

Ainsworth, M. D. S., \& Wittig, B. (1969). Attachment and exploratory behavior of one-year- olds in a strange situation. In B. M. Foss (Ed.), Determinants of infant behavior (Vol. 4). London: Methuen.

Bakeman, R., \& Brown, J. V. (1980). Early interaction: Consequences for social and mental development at three years. Child Development, 51 , 437-447.

Beckwith, L., Cohen, S. E., Kopp, C. B., Parmelee, A. H., \& Marcey, T. G. (1976). Caregiver-infant interaction and early cognitive development in preterm infants. Child Development, 47, 579-587.

Bell, S. M., \& Ainsworth, M. D. S. (1972). Infant crying and maternal responsiveness. Child Development, 43, 1171-1190.

Belsky, J. (1984). The determinants of parenting: A process model. Child Development, 55, 83-96.

Belsky, J., Rovine, M., \& Taylor, D. G. (1984). The Pennsylvania infant and family development project. III: The origins of individual differences in infant-mother attachment: Maternal and infant contributions. Child Development, 55, 718-728.

Belsky, J., Taylor, D. G., \& Rovine, M. (1984). The Pennsylvania infant and family development project, I1: The development of reciprocal interaction in the mother-infant dyad. Child Development, 55, 706-717.

Benn, R.K., (1985). Factors associated with security of attachment in dual career families. Society for Research in Child Development, Toronto, May, 1985. 
Bornstein, M. H., \& Tamis-LeMonda, C. S. (1988). Maternal responsiveness and cognitive development in children. In M. H. Bornstein (Ed.), Maternal responsiveness: Characteristics and consequences. New directions for child development, 43, San Francisco: Jossey-Bass.

Caims, R. B., \& Green, J. A. (1979). How to assess personality and social patterns: Observations or ratings. In R. B. Cairns (Ed.), The analysis of social interactions: Methods, issues and illustrations. New Jersey:Hilsdale.

Clark, G. N., \& Seifer, R. (1985). Assessment of parents' interactions with their developmentally delayed infants. Infant Mental Health Society Journal, 6 (4), 214-225.

Clarke-Stewart, K., \& Hevey, C. M. (1981). Longitudinal relations in repeated observations of mother-child interaction from 1 to $21 / 2$ years. Developmental Psychology, 17 (2), 127-145.

Cohn, J. F., Matias, R., Tronick, E. Z., Connell, D., \& Lyons-Ruth, K. (1986). Face-to face interactions of depressed mothers and their infants. In E.Z. Tronick, T. Field (Eds.), Maternal depression and infant disturbance. New directions for child develepment, 34, San Francisco: Jossey-Bass.

Crockenberg, S., \& McCluskey, K. (1985, May). Predicting infant attachment from early and current behavior of mothers and infants. Paper presented at the meeting of the Society for Research in Child Development, Toronto, Canada.

Donovan, W. L., \& Leavitt, L. A. (1978). Early cognitive development and its relation to maternal physiologic and behavioral responsiveness. Child Development, 49, 1251-1254.

Egeland, B., \& Farber, E. A. (1984). Infant-mother attachment: Factors related to its development and changes over time. Child Development, 55, 753771.

Farran, D., Kasari, C., Comfort-Smith, M., \& Jay, (1986). Parent $/$ Caregiver Involvement Scale. For further information contact Dale Farran, Child Development - Family Relations, University of North Carolina at Greensboro.

Farran, D. C., Comfort-Smith, M., \& Kasari. C. (1985, April). Factors affecting parent-child interactions with young handicapped children. Poster presented at the biennial meeting for Research in Child Development, Toronto, Canada.

Farran, D., Kasari, C., Yoder, P., Harber, L., Huntington, G., \& Comfort-Smith, M. (1987). Rating mother-infant interactions in handicapped and at-risk infants. In D. Tamir (Ed.), Stimulation and intervention in infant development. London: Freund Publishing. 
Field, T. Interactions of preterm infants born to lower SES, teenage mothers. (1980). In T. Field, S. Goldberg, D. Stern \& A. Sostek (Eds.), Interactions of high-risk infants and children. New York: Academic Press.

Field, T., Healy, B., Goldstein, S., Perry, S., Bendell, D., Schanberg, S., Zimmerman, E. A., \& Kuhn, C. (1988). Infants of depressed mothers show "depressed" behavior even with nondepressed adults. Child Development, 59, 1569-1579.

Fogel, A., \& Thelan, E. (1987). Developmet of early expressive and communicative action: Reinterpreting the evidence from a dynamic systems perspective. Developmental Psychology, 23 (6), 747 761.

Garcia-Coll, C. (in progress). Behavioral assessment of infant temperament.

Goldsmith, H., \& Alansky, J. (1987). Maternal and infant temperamental predictors of attachment: a meta-analytic review. Lournal of Consulting and Clinical Psychology. 55, 805-816.

Grossmann, K., Grossmann, K. E., Spangler, G., Suess, G., \& Unzner, L. (1985). Maternal sensitivity and newborns' orientation responses as related to quality of attachment in Northern Germany. Monographs of the Society for Research in Child Development, 44 (1-2, Serial No. 209).

Isabella, R. A., Belsky, J., \& von Eye, A. (1989). Origins of infantmother attachment: An examination of interactional synchrony during the infant's first year. Developmental Psychology, 25 (1), 12-21.

Isabella, R. A., \& Belsky, J. (1991). Interactional synchrony and the origins of infant-mother attachment: A replication study. Child Development, 62 , 373-384.

Jay, S. The validation of a mother-child interaction rating scale. Unpublished doctoral dissertation, Duke University, 1979.

Jay, S., \& Farran, D. (1981). The relative efficacy of predicting IQ from mother-child interactions using rating versus behavioral count measures. Journal of Applied Developmental Psychology, $2,165-177$.

Kaye, K., \& Fogel, A. (1980). The temporal structure of the face-to-face communication between mothers and infants. Developmental Psychology, 16 (5), 454-464.

Levine, L., Garcia Coll, C.T., \& Oh, W. (1985). Determinants of mother-infant interaction in adolescent mothers. Pediatrics, 75 (1), 23-29. 
Lewis, M., \& Feiring, C. (1989). Infant, mother, and mother-infant interaction behavior and subsequent attachment. Child Development, 60, 831-837.

Lyons-Ruth, K., Connell, D. B., Zoll, D., \& Stahl, J. (1987). Infants at social risk: Relations among infant maltreatment, matemal behavior, and infant attachment behavior. Developmental Psychology, 23 (2), 223-232.

Main, M. (1983). Exploration, play and cognitive functioning related to infant-mother attachment. Infant Behavior and Development, 6, 167. 174.

Mayer, N. K., \& Tronick, E. Z. (1985). Mothers' tum-giving signals and infant turn-taking in mother-infant interaction. In T. M. Field \& N. A. Fox (Eds.), Social perception in infants. New Jersey: Ablex Publishing.

Moran, G., Pederson, D.R., Pettit, P. \& Krupka, A. (in press). Maternal sensitivity and infant-mother attachment in a developmentally delayed sample.

O'Brien, M., Johnson, J. M., \& Anderson-Goetz, D. (1989). Evaluating quality in mother-infant interaction: Situational effects. Infant Behavior and Development, 12, 451-464.

Park, K. A., \& Waters, E. (1989). Security of attachment and preschool friendships. Child Development, 60, 1076-1081.

Patterson, J. C., Cohn, D. A., \& Kao, B. T. (1989). Maternal warmth as a protective factor against risks associated with peer rejection among children. Development and Psychopathology, 1, 21-38.

Pederson, D. R., Moran, G., Sitko, C., Campbell, K., Ghesquire, K., \& Acton, H. (1989, May). Matemal sensitivity and the security of infant-mother attachment: A Q-sort study. Society for Research in Child Development, Kansas City, MO.

Pederson, D. R., Moran, G., Sitko, C., Campbell, K., Ghesquire, K., \& Acton, H. (1990).. Maternal sensitivity and the security of infant-mother attachment: A Q-sort study. Child Development, 61, 1974-1983.

Radke-Yarrow, M., Cummings, E. M., Kuczynski, L., \& Chapman, M. (1985). Pattems of attachment in two- and three-year-olds in normal families and families with parental depression. Child Development, 56, 884-893.

Ragozin, A. S., Basham, R. B., Cmic, K. A., Greenberg, M. T., \& Robinson, N. (1982). Effects of maternal age on parenting role. Developmental Psychology, 18 (4), 627-634.

Roggman, L. A., Langlois, J. H., \& Hubbs-Tait, L. (1987). Mothers, infants, and toys: Social play correlates of attachment. Infant Behavior and Development, 10, 233-237. 
Sameroff, A. J., \& Chandler, M. J. (1975). Reproductive risk and the continuum of caretaking casualty. In F. D. Horowitz, M.

Hetherington, S. Scarr-Salapatek \& G. Siegel (Eds.), Review of child development research (Vol.4, pp. 187-244). Chicago: The University of Chicago Press.

Seifer, R. (in process). Assessing infant temperament using aggregate methods. NIMH funded research project in progress, Bradley Family Research Center, Providence, RI.

Seifer, R., Clark, G.N. \& Sameroff, A.J. (1991). Positive effects of interaction coaching on infants with developmental disabilities and their mothers. American Joumal of Mental Retardation 96, 1-11.

Schneider-Rosen, K., Braunwald, K. G., Carlson, V., \& Cicchetti, D. (1985). Current perspectives in attachment theory: Illustration from the study of maltreated infants. Monographs of the Seciety for Research in Child Development, 44 (1-2, Serial No. 209).

Stem, D. (1977). The first relationship: Mother and infant. Cambridge: Harvard University Press.

Tronick, E. Z., (in process). Maternal Sensitivity and Responsivity Scale.

Tronick, E., Als, H., \& Brazelton, T. B. (1980). Monadic phases: A structural descriptive analysis of infant-mother face to face interaction. MerrillPalmer Quarterly, 26, 5-24.

Vaughn, B.E. \& Waters, E. (1990). Attachment behavior at home and in the laboratory: Q-sort observations and strange situation classifications of one-year-olds. Child Development, 61, 1965-1973.

Waters, E. (1978). The reliability and stability of individual differences in infant-mother attachment. Child Development, 49, 483-494.

Waters, E., \& Deane, K. (1985). Defining and assessing individual differences in attachment relationships: Q-methodology and the organization of behavior in infancy and early childhood. In I. Bretherton \& E. Waters (Eds.), Growing points of attachment theoryand research (pp 41-65). Monographs of the Society for Reseacth in Child Development. 50 (1-2, Serial No. 209). 